[Radiocarbon, Vol 22, No. 2, 1980, P 260-266]

\title{
COMPUTER-MATCHED RADIOCARBON DATES OF FLOATING TREE-RING SERIES
}

\author{
H H KRUSE*, T W LINICK, H E SUESS
}

Mt Soledad Radiocarbon Laboratory, University of California, San Diego, La Jolla, California 92093

\author{
and BERND BECKER
}

Institut für Botanik, Universität Stuttgart-Hohenheim, 7000 Stuttgart 70, West Germany

\begin{abstract}
The absolute time of growth of a floating tree-ring series is determined by computer, by first fitting a curve to the ${ }^{14} \mathrm{C}$ ages of tree-ring dated wood and then by matching the ${ }^{14} \mathrm{C}$ ages of the floating tree-ring series to that curve. The results obtained by this matching procedure are given here for five floating European oak chronologies for which ${ }^{14} \mathrm{C}$ dates have been published previously by Suess (1978). Three of these five floating series have been linked together dendrochronologically. There now remain three floating series covering a 4000 -year time span from $4820 \mathrm{BC}$ to $830 \mathrm{BC}$. Their ${ }^{14} \mathrm{C}$ dates, matched by computer to the bristlecone pine chronology, provide a possibility of obtaining precise ages of oak wood series from Neolithic sites in Switzerland and South Germany by dendrochronologically cross-dating with the calibrated master chronologies.
\end{abstract}

\section{METHOD}

The method of "wiggle matching" to derive accurate radiocarbon ages of wood with annual rings belonging to so-called "floating tree-ring sequences" was first used by Ferguson, Huber, and Suess (1966). The method makes use of the fact that wood samples grown during the same period of time show not only the same ${ }^{14} \mathrm{C}$ content, but also the same time derivative of their ${ }^{14} \mathrm{C}$ content, as deduced from the $\Delta^{14} \mathrm{C}$ change within the respective wood series. Since 1966, a large number of floating tree-ring chronologies have been established, some of them more than 1000 or even 2000 years long (Becker, 1979; Pearson and others, 1977). Results of ${ }^{14} \mathrm{C}$ measurements from such chronologies have been reported previously (Suess and Becker, 1977; Suess, 1978; de Jong and Mook, 1979). The "zero points" of these floating chronologies were estimated visually by comparing plots of conventional radiocarbon ages versus tree-ring numbers of floating series and of radiocarbon age versus calendar year for known-age series, respectively. A more rigorous method of deriving dates for floating tree-ring chronologies is described by Beer and others (1979). Essentially the same method is applied here.

For floating tree-ring series, the oldest (innermost) ring of the oldest specimen of wood, $i e$, the starting year of growth of the entire sequence, generally is assigned ring number one; therefore, tree-rings of decreasing true age have increasing ring numbers. By visually matching the general ${ }^{14} \mathrm{C}$ age trend of the floating series with the calibration curve for knownage wood of equivalent ${ }^{14} \mathrm{C}$ age, an estimation of the absolute age of the floating series can be made. The accuracy of this estimation is improved if short-term variations (so-called "wiggles") in both the floating and known-age curves are present. By fixing the zero point date, the estimated

* Present address: Max-Planck-Institut für Chemie, Abt Kosmochemie, 65 Mainz, West Germany 
calendar year of growth of each ring of a series can be calculated by adding the tree-ring number to the zero point year (AD years given positive arithmetic signs, BC years given negative signs, a calendar year zero is included here, contrary to traditional historical usage).

A computer method of performing this matching is presented here. Routinely, one data card is manually punched for each counting of a sample. This card includes LJ number, descriptive information, date of counting, gross disintegrations per minute and statistical uncertainty of that quantity, and $\delta^{13} \mathrm{C}(\%$ PDB). Coded data cards containing the values of the counter background, net standard, and the uncertainties in those quantities to be applied to the following sample count rates are inserted into the deck where appropriate. Program C14TLC7 calculates $\Delta^{14} \mathrm{C}$ values and radiocarbon ages for each measurement. Weighted averages of the results from different countings of the same sample are calculated, with the weighting proportional to the inverse squares of the uncertainties. A print-out lists all individual measurement results and averages, first ordered in the sequence of measurement, and secondly ordered in a sequence of decreasing known (or estimated) true age or, if there is no available true age value (year AD 1950 assumed for calculation purposes), by increasing LJ number. The computers (CDC 3600 and Burroughs 6700) can also be requested to punch cards giving the weighted average results for each sample. It is these cards that are used for the computer matching procedure.

The computer matching procedure is performed as follows: The data inputs are 1) the computer-punched data cards for known-age wood, covering a time period extending slightly longer (ca 100 years) at both extremes than that covered by the floating series, and 2) the computer-punched cards for the floating series; each of the two data sets is separately arranged in order of decreasing actual ages. In order to obtain a starting point for the computer matching, a tree-ring year is chosen, defining an estimated zero point year. The program MATCH first determines a smooth cubic spline function (Reinsch, 1967) for the radiocarbon ages of the known-age wood versus the true calendar years of growth. The degree to which this curve is smoothed is determined by a smoothing factor which may be varied from zero (natural cubic spline, viz curve follows points exactly) to one (highly smoothed). The program then calculates, for the entire floating series, the sum of the squares of the differences between the ages of the individual floating samples and the spline curve age values for the corresponding years. If $\mathrm{n}$ denotes the number of floating samples, $t_{i}$ the assumed calendar year of floating sample $i, A_{i}$ the measured ${ }^{14} \mathrm{C}$ age of floating sample $i$, and $S\left(t_{i}\right)$ the ${ }^{14} \mathrm{C}$ age value of the spline function for $t_{i}$, then, the sum calculated is:

$$
\sum_{i=1}^{n}\left[A_{i}-S\left(t_{i}\right)\right]^{2} \equiv Y
$$

This sum is calculated for each assumed zero point year successively at 2.5-year intervals on both sides of the zero point year originally esti- 
mated. The zero point year for which this sum is minimized represents the best, revised zero year of the respective tree-ring series. The computer print-out lists the result as the difference in years relative to the zero point year originally assumed. Plots are also generated by the computer such as shown on the figures: 1) of the sum of squares of differences versus offset in years from the original estimate, 2) of the calibration curve $\left({ }^{14} \mathrm{C}\right.$ age $\mathrm{BP}$ versus calendar year, axes rotated $\left.45^{\circ}\right)$ including known-age points (circles) with error bars, matched floating points (stars) with error bars, and the spline curve.

In order to test the method, especially for cases in which the number of experimental values of the floating series is larger than the number of values for the known-age series, reversing the procedure seems to be indicated. This is done by fitting a spline curve to the floating series data and by fitting the known-age data to that curve. In matching results given below, the differences in the two directions of matching are generally less than twenty years (except for the D8 series). The zero year finally obtained constitutes the average of the two results, weighted proportionally to the number of values in the two synchronous data sets, $i e$, the result for the match to the curve based on more data points is more heavily weighted.

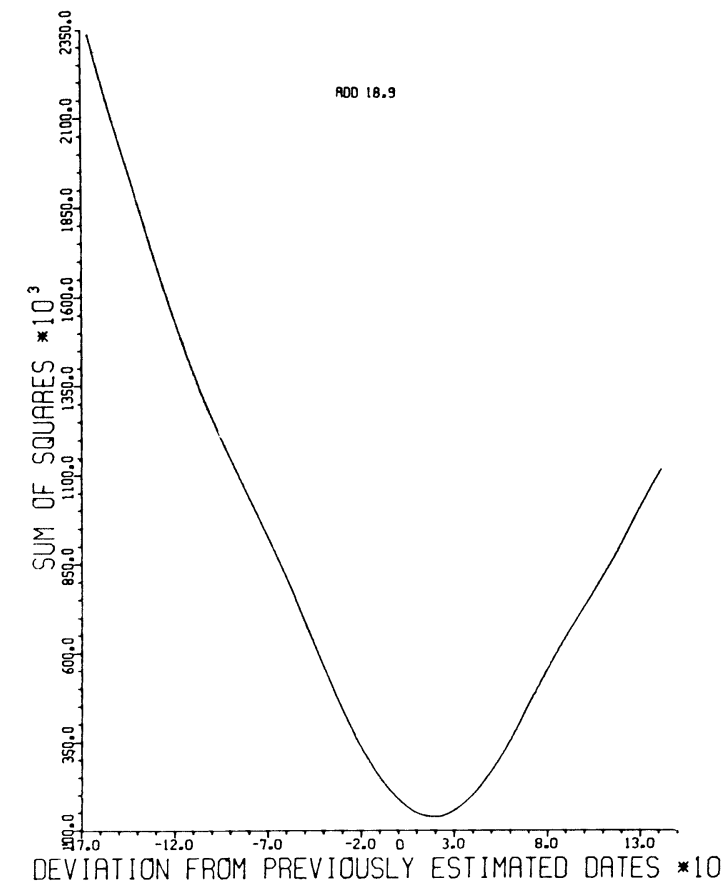

Fig 1. Matching of ${ }^{14} \mathrm{C}$ ages of Becker Donau $7 / 9 / 12$ floating series to those of known-age bristlecone pine samples: $\mathrm{Y}$, sum of squares of differences of ${ }^{14} \mathrm{C}$ ages of floating samples from spline curve values, versus differences of zero-point years from starting zero year 4059 BC. Plot indicates that +18.9 years should be added to starting zero point of $4059 \mathrm{BC}(-4059)$ to give new zero point of -4040 . 
An example of the plots generated by the matching procedure is given here for the Becker Donau 7/9/12 series. $4059 \mathrm{BC}$ was taken as the starting zero year. First, a spline curve was derived from the known-age bristlecone pine ${ }^{14} \mathrm{C}$ data for the relevant time span. The data for the floating series was matched to the spline curve. This is illustrated in figure 1, which is a plot of the sum of squares of ${ }^{14} \mathrm{C}$ age differences $\mathrm{Y}$ versus offset of zero year relative to the original starting zero point year. Figure 2 shows the calibration curve $\left({ }^{14} \mathrm{C}\right.$ age versus calendar year, rotated $\left.45^{\circ}\right)$. The spline curve here is fitted only to the known-age points (shown as circles). The floating series points (shown as stars) are plotted according to the calendar years provided by the computer-matching. Figure 3 is the same type of plot as figure 1, except that the spline curve was first fit to the floating data series, and the known-age data were matched to that curve. Figure 4 is the calibration curve resulting from the reversed matching procedure. Since there were 39 known-age samples and 57 floating samples from the same time period, the reversed match result was given higher weighting. The sign of the zero point year change shown in figure 3 is the opposite of that which should be applied to the floating series. Thus, the weighted average of +18.9 years (from normal matching) and +33.3 years (from reversed matching) is +27 years; when added to the starting zero point year of 4059 BC (or -4059 ), this gives the zero point year of $4032 \mathrm{BC}$.

\section{RESULTS}

In Suess (1978), ${ }^{14} \mathrm{C}$ ages were given for eight floating tree-ring series. These series have been derived mainly by the Stuttgart-Hohenheim Tree-Ring Laboratory. Subfossil oak trees dredged out from postglacial gravel deposits along the rivers Danube and Main (Becker Donau/Main series were used).

Unfortunately, it is impossible to use a matching procedure for the three oldest series, viz 1) the Fischbeck series (estimated zero point ca $6120 \mathrm{BC})$, 2) the Becker Donau 11 incomplete series, and 3) the Becker

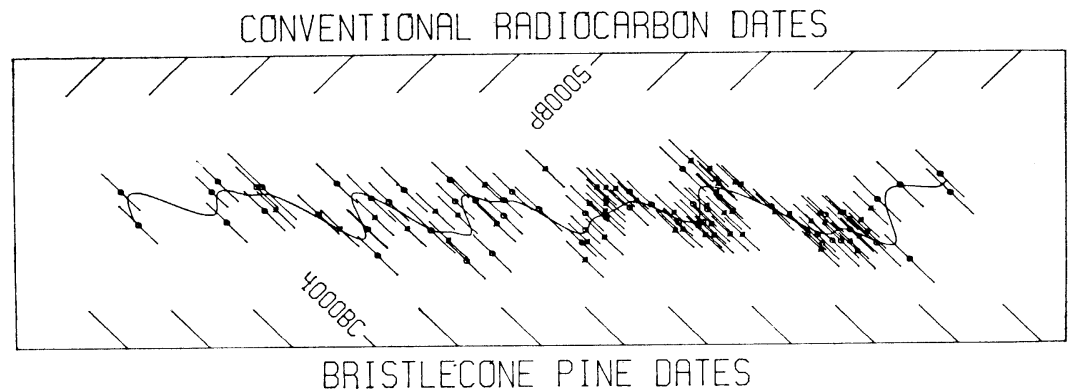

Fig 2. Calibration curve of ${ }^{14} \mathrm{C}$ ages ${ }^{\mathrm{BP}}$ (“Conventional Radiocarbon Dates") versus calendar years ("Bristlecone Pine Dates") for Donau 7/9/12 series and contemporaneous bristlecone pine samples, respectively. Curve is fit to known-age bristlecone pine wood data only. Circles are known-age measurements, stars are floating series measurements plotted corresponding to their computer-matched calendar years. Ages increase to left, with one scale division per hundred years. 


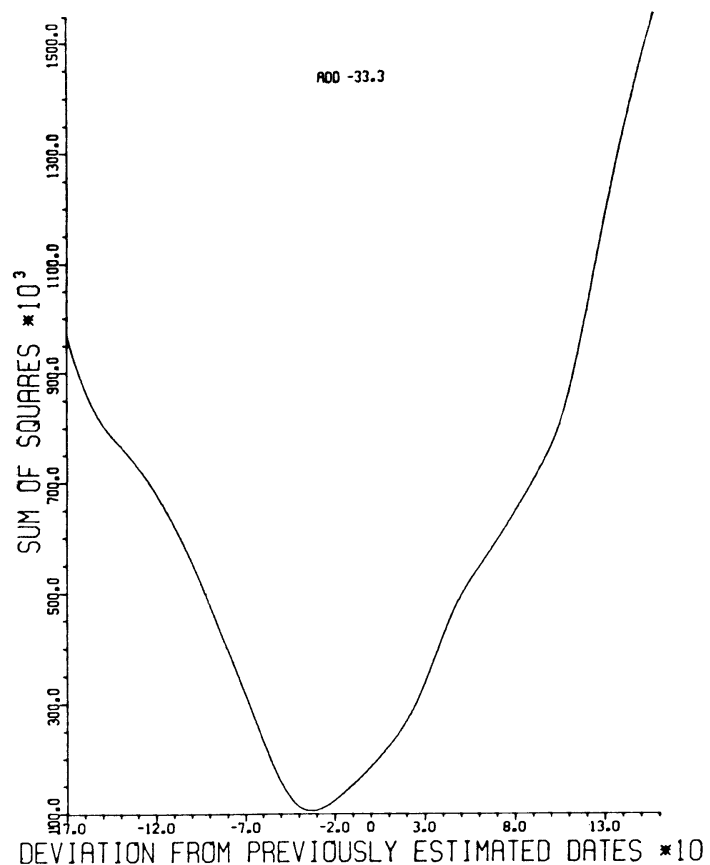

Fig 3. Reversal of matching procedure of figures 1 and 2, plot corresponding to figure 1. Spline curve fit to floating series data, known-age data matched to that curve. Sign of prescribed adjustment of calendar years is opposite of that to be applied to floating series, $i e,+33.3$ years should be added to assumed zero-point year of floating series, -4059 to give a new zero point of -4026 .

Main 6 series (estimated zero point ca $6075 \mathrm{BC}$ ). The reason is that there must, of course, be ${ }^{14} \mathrm{C}$ values for known-age wood spanning the age range of the floating series to be matched. The only data for known-age wood from earlier than 5407 BC determined by this laboratory are measurements of eight ten-year samples of bristlecone pine from the period $6050 \mathrm{BC}$ to $5960 \mathrm{BC}$. The matching technique described here has been applied to the Becker Donau 8 series, the Becker Neolithic master chronology (Donau 7/9/12 series, with Thayngen-Burgaschisee samples omitted because of the uncertainty in reconstructing the tree-ring scale used by the late B Huber for this chronology), the Becker Main 5 series, the Becker Donau 3/10 series, and the Zug-Sumpf series of V GiertzSiebenlist-Kerner. The results are given in table 1. Statistical uncertainties in the computer-matched zero point years are not given, because it is a very complex mathematical problem to calculate defined errors. From use of both the normal and reversed matching procedures and from observation of the effect of variation of the degree of curvesmoothing upon the result, it appears that the uncertainty is of the order of \pm 10 years for all except the Donau 8 series (uncertainty of \pm 30 years).

Since the calculation of these values, the Hohenheim series Donau 7/9/12, Main 5 and Donau 3/10 have been linked together dendrochrono- 
TABLE 1

Computer-matched zero point years for five floating German oak series

\begin{tabular}{lccc}
\hline \multicolumn{1}{c}{ Series } & $\begin{array}{c}\text { No. of rings } \\
\text { in series }\end{array}$ & $\begin{array}{c}\text { Previously } \\
\text { published } \\
\text { zero point }\end{array}$ & $\begin{array}{c}\text { Computer-matched } \\
\text { zero point }\end{array}$ \\
\hline Donau 8 & 300 & $4430 \mathrm{BC}$ & $4400 \mathrm{BC}$ \\
Donau $7 / 9 / 12$ & 800 & $4050 \mathrm{BC}$ & $4032 \mathrm{BC}$ \\
Main 5 & 450 & $3250 \mathrm{BC}$ & $3262 \mathrm{BC}$ \\
Donau 3/10 & 1250 & $2860 \mathrm{BC}$ & $2871 \mathrm{BC}$ \\
Zug-Sumpf & 300 & $1250 \mathrm{BC}$ & $1238 \mathrm{BC}$ \\
\hline
\end{tabular}

logically into one continuous floating master chronology. This NeolithicBronze age series represents, at present, 2342 tree rings. In order to compare this long series with the La Jolla dates obtained for the three parts of this series (Suess, 1978), one must add 780 years to the Main 5 tree-ring numbers, and 1009 years to the Donau 3/10 tree-ring numbers. For the Main 5 series, the computer-matched zero point (3262 BC) differs by only 10 years from the dendrochronologic zero point of 3252 BC, obtained by subtracting 780 years from the zero point $(4032 \mathrm{BC})$ of the Donau 7/9/12 series. However, there is a discrepancy of 152 years between the computermatched zero point 2871 BC of Donau $3 / 10$, which dendrochronologically dates 3023 вс. This discrepancy cannot yet be explained.

The Groningen Laboratory has carried out high precision ${ }^{14} \mathrm{C}$ analyses of rings 250 to 850 of the D 7/9/12 series (de Jong, Mook, and Becker, 1979). These results clearly reproduce the wiggles found by La Jolla. De Jong calibrates the zero point for D $7 / 9 / 12$ as $4035 \pm 3$ BC, essentially identical with our matched zero point of 4032 BC. Other prehistoric floating oak chronologies for which computer-matched zero points are listed in table 1 have also been considerably extended in the meantime, as listed in table 2.

A period of nearly 4000 years (4826 BC to $830 \mathrm{BC}$ ) is now covered by the three floating oak chronologies of the Hohenheim Laboratory. These three chronologies, in combination with the method of computer matching, provide a very accurate and reliable basis for age determinations of prehistoric settlements in South Central Europe. In cooperation with the Tree-Ring Laboratories of Neuenburg (Lambert, Orcel, and

TABLE 2

Extent of floating German oak chronologies, with dates normalized to computer-matched zero points as listed in table 1. Right-hand column:

Zero point year as given in table 1 of the first individual series listed on each line minus zero point of extended series.

\begin{tabular}{lcc}
\hline Extended series & Period & $\begin{array}{c}\text { Extension of series } \\
\text { at older end }\end{array}$ \\
\hline Donau 8/15-Main 18 & $4826-4090$ BC & 427 \\
Donau 7/9/12-Main 5-Donau 3/10 & $4058-1717$ BC & 27 \\
Zug-Sumpf-Donau 14-Main 15 & $1474-830$ BC & 237 \\
\hline
\end{tabular}

(The chronologies were developed by Bernd Becker in cooperation with A Delorme, University of Göttingen). 


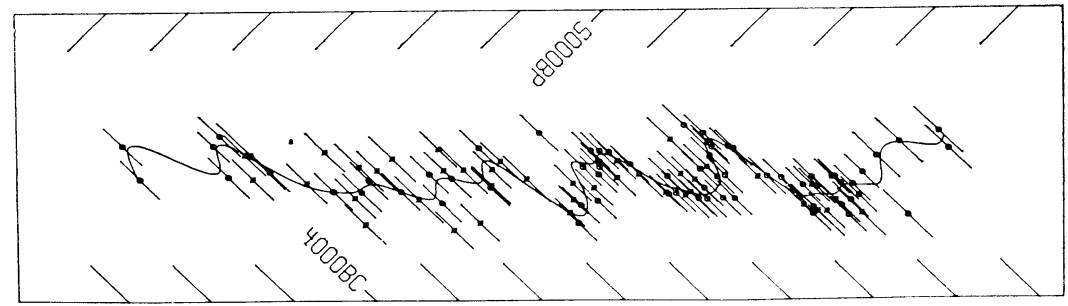

\section{BRISTLECONE PINE DATES}

Fig 4. Calibration curve plot from reversed matching procedure. Curve is fit to floating series data only. Circles are floating series measurements plus known-age wood measurements for ends of range; stars are known-age bristlecone pine measurements adjusted by +33.3 years offset determined by computer. Plot is illustrative of method, but is not technically correct, because known-age wood calendar years are changed in the figure.

Egger), Zürich (Ruoff), and Louvain (Munaut), more than 70 cutting dates of prehistoric lake dwellings covering the time range from $3850 \mathbf{B C}$ to $2400 \mathrm{BC}$ and from $1100 \mathrm{BC}$ to $900 \mathrm{BC}$ can be dated now by an indirect cross-calibration with La Jolla dates. This is being achieved by dendrochronologic cross-correlation of the oak tree-ring chronologies from lake dwellings in Switzerland and in South Germany with the NeolithicBronze age and the Late Bronze age calibrated floating tree-ring series listed in table 2 (Becker, 1979; Becker and others, 1979).

\section{ACKNOWLEDGMENTS}

We appreciate financial support through NSF Grant ATM77-21770 from the Atmospheric Science Section, which provided the possibility for mathematical analyses of La Jolla radiocarbon data.

\section{REFERENCES}

Becker, Bernd, 1979, Holocene tree-ring series from southern central Europe for archaeology dating, radiocarbon calibration, and stable isotope analysis, in Berger, Rainer and Suess, $\mathbf{H}$ E, eds, Radiocarbon dating, Internatl radiocarbon conf, 9th, Proc: Berkeley/Los Angeles, Univ California Press, p 554-565.

Becker, Bernd, Orcel, C, Egger, E, and Ruoff, U, 1979, Drei Beiträge zur Chronologie des Neolithikums in der Schweiz: Zeitschr Schweiz Archäol Kunstgesch, v 36, H2, p $91-96$.

Beer, J, Giertz, V, Möll, M, Oeschger, H, Riesan, T, and Storhm, C, 1979, The contribution of the Swiss lake-dwellings to the calibration of radiocarbon dates, in Berger, Rainer and Suess, H E, eds, Radiocarbon dating, Internatl radiocarbon conf, 9th, Proc: Berkeley/Los Angeles, Univ California Press, p 567-584.

Ferguson, C W, Huber, B, and Suess, H E, 1966, Determination of age of Swiss lake dwellings as an example of dendrochronologically-calibrated radiocarbon dating: Zeitschr Naturforschung, v 21a, p 1173-1177.

de Jong, A F M, Mook, W G, and Becker, Bernd, 1979, Confirmation of the Suess wiggles: Nature, v 280, p 48-49.

Pearson, G W, Pilcher, J R, Baillie, M G L, and Hillam, J, 1977, Absolute radiocarbon dating using a low altitude European tree-ring calibration: Nature, v 270, p 25-28.

Reinsch, C H, 1967, Smoothing by spline functions: Numerische Mathematik, v 10 , p $177-183$.

Suess, H E, 1978, La Jolla measurements of radiocarbon in tree-ring dated wood: Radiocarbon, v 20, p 1-18.

Suess, H E and Becker, Bernd, 1977, Der Radiocarbongehalt von Jahresringproben aus postglazialen Eichenstämmen Südmitteleuropas, in Dendrochronologie und Postglaziale Klimaschwankungen in Europa: Erdwiss Forschung, v 13, p 15-170. 